\section{Looking beyond creature comforts}

\section{Marian Stamp Dawkins}

Laboratory Animal Husbandry: Ethology, Welfare and Experimental Variables. By Michael W. Fox. State University of New York Press: 1986. Pp.267. Hbk \$39.50; pbk $\$ 9.95$

I MUST confess that most books on animal welfare give me a sinking feeling even before I read them. I have a prejudice, no doubt grossly exaggerated and unrelated to the real world, that there are only two types of book about this subject. The first treats animals in a mystic, reverential way and castigates humans for interfering in the natural balance of things and, sometimes, for having anything to do with animals at all. The other goes to the opposite extreme and talks mostly about sq $\mathrm{cm}$ of cage size and the regular collection of faeces. There seems to be little in between: it is as if one has either to be poetical in one's attitude to animals or adopt the earthiest sort of banality about the size of their cages or the cleanliness of their drinking water.

The sinking feeling occurred when I first looked at Laboratory Animal Husbandry by Michael W. Fox. However, despite its title, the book certainly does not fall into either of the usual categories. On the contrary, it is innovative in several important ways.

First, it documents recent evidence about the effects that totally unexpected factors may have on animal health and well-being. It is perhaps not surprising that noise, ventilation and ambient temperature can have significant effects on the health of animals and their susceptibility to disease. But it is probably less well known that the exact age of weaning and the amount of handling from a human being can affect, among other things, plasma cortiscosterone, prolactin and growth hormone levels. The behavioural and physiological changes that have been found can in turn affect not only the animals" own well-being but the results of experiments on, say, drugs. Some of these unexpected factors may radically alter the conclusions about how effective a treatment is.

A second, related point that Fox makes concerns an animal's social environment. It should be obvious, but it clearly is not to judge from current practice, that an animal's welfare cannot be safeguarded simply by concentrating on the bare necessities of food and water or even on the physical environment of its cage. Many animals are highly social. They interact, both positively and negatively, with other members of their species; it should not be
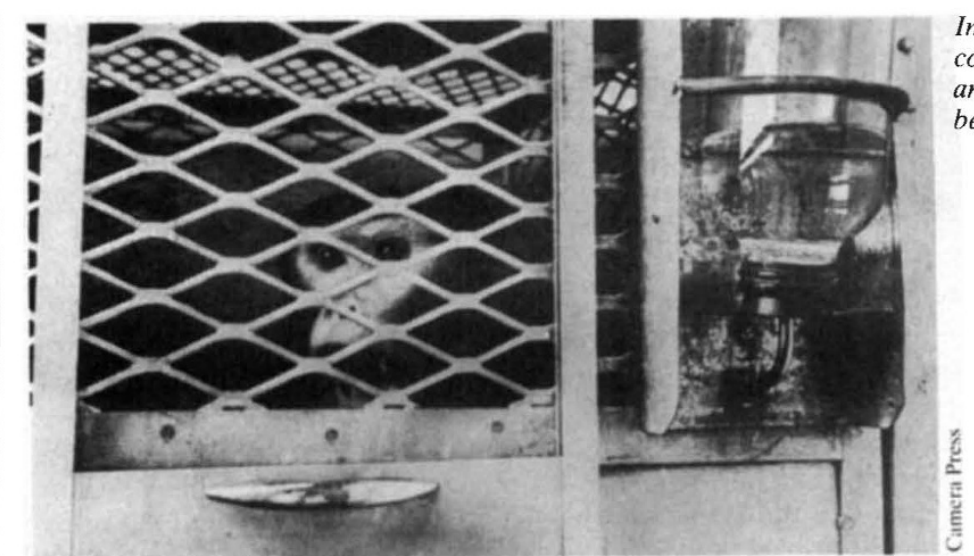

Improved conditions for animals could benefit humans too

surprising, therefore, that disturbances in their social lives can significantly affect their behaviour and health. Fox argues that our understanding of human ailments is far from complete and it is often impossible to pinpoint why one person becomes ill when another does not. If we are attempting to use animals as models of puzzling human diseases, he argues, we will continue to be ignorant unless we also begin to consider the complexity of the factors, including social ones, that affect the development of diseases in animals.

He concludes that there is a double imperative on us to improve the welfare of laboratory animals. One is for the animals themselves: if we use them we should look after their welfare better than we do now by taking into account the range of factors, both physical and social, that can affect them. The other is for humans: if we want good scientific results, we should be more careful about the conditions in which we keep animals. There follows a useful chapter giving practical suggestions as to how laboratory animal husbandry could be improved for the benefit of both human and non-human animals. Another chapter contains a review of the main findings on pain and suffering in research animals.

One particularly appealing feature of the book is that the discussion of animal rights is kept to the last chapter. This means that even if you disagree with Fox on this issue or lose sympathy with the "land ethic" or "One Medicine", the rest of the book with its more down-to-earth reviews and suggestions, loses none of its value. The ethical issues are discussed but they do not intrude, so that the book can potentially appeal to, and be profitably read by, people with very divergent attitudes to animals.

The common thread is a concern for the welfare of animals in laboratories. Fox's contribution is to bring common-sense and research findings to bear on the problem of how we might improve it. He points to the arbitrariness of the present guidelines and laws as to how animals should be kept (the fact that recommended cage sizes for dogs, cats and primates in Britain are double those suggested by the
American authorities, for instance). And his insistence that we should take more notice of the social needs and interactions of animals, and not just think in terms of their physical comfort, is a message that cannot be broadcast too loudly or too frequently.

Marian Stamp Dawkins is Fellow in Biological Sciences at Somerville College, Oxford OX2 $6 H D, U K$. She is also author of Animal Suffering: the Science of Animal Welfare (Chapman \& Hall, 1980).

\section{Economical images}

\section{Peter Hawkes}

Transform Coding of Images. By R.J. Clarke. Academic: 1985. Pp.432. Hbk. $\$ 69.50, £ 60.50 ; \mathrm{Pbk} . \$ 34.95, £ 31$.

FROM the point of view of a computer, an image is a voluminous and cumbersome object. The human eye and brain can handle a continuous-tone picture effortlessly and almost instantaneously; for a computer, the image must be broken into small zones, each of which corresponds to a number representing the grey-level. There are typically 256 of the latter, and the number of image-elements or "pixels" can easily reach a million. For these values the computer already has 8 megabits to cope with, but if the image is coloured rather than black-and-white this must be multiplied by three. Worse still, although we may regard such an image as a $1024 \times$ 1024 matrix, each element of which is an (eight-bit) number representing the greylevel of the corresponding pixel, in image processing we are also interested in statistical properties. If the image is represented by an $\mathrm{N} \times \mathrm{N}$ matrix $(\mathrm{N}=1024$ in our example), then the matrix corresponding to such statistics will be $\mathrm{N}^{2} \times \mathrm{N}^{2}$.

Everyday images contain much redundant information - uniform or slowly varying areas for example - and it is natural to ask whether a typical image could not be represented in the computer in a more economical way. This question has long preoccupied the image proces- 